\title{
Research and practice to enhance the ability of teachers
}

\author{
Ding You Qing \\ Chongqing University of Science and Technology, Chongqing, China
}

Keywords: Teaching ability; Engineering practice; Education quality; Higher education; Teacher training

\begin{abstract}
In recent years, the development of universities is very rapid. In order to meet the needs of teaching, local colleges and universities focuse on the introduction of a significant number of doctoral students to enrich teachers. With the increasing expansion of college enrollment, young university teacher has more than 30,000 annual increment. A large number of young people have got doctoral, master degree and got into university or college. These graduates are early as teachers, have no experiences in teaching, especially in engineering practice have immature performance abilities. With connection to mechanical discipline, this paper presents the appropriate methods about young teachers to strengthen their basic training skills and to enhance their practice abilities.
\end{abstract}

\section{Introduction}

In China, the higher education has changed from big country to powerful country. In this case, to enhance the ability of teachers, especially to improve the ability of engineering practice is the urgent requirement for higher education from the "quantitative expansion" to "content development, quality improvement". It is not only the key to improve higher education quality and to promote education reform, but also the needs for teacher to develop themself. Higher educated, younger teacher is the feature of college and university. Universities as an important place of cultivating talent, its teaching quality determines the quality of its personnel training. In a number of factors affecting the quality of teaching, the teaching ability of teachers is an important factor. In China, young teachers arean important part of the university teachers and its teaching abilities directly affect the teaching quality of personnel training. How to improve the teaching ability of young teachers is an important job in universities. Studies have shown that: young university teachers have their own advantages, but their teaching abilities, such as managing the teaching content, individualized, unscripted lectures, teaching innovation ability, reflection and research, are relatively lacking. The important factors of national policy, before school vocational training system, teaching seminars, mentoring, lectures competitions, teaching reflection, teacher training institutions and subjective factors affect the development of young teachers teaching abilities.

\section{College Upgrading Scheme}

In close connection with the development requirements of University of Applied Sciences, as well as to meet the needs of practical teaching, the upgrading principle has been decided as "on-demand training, apply their knowledge". It is good to effectively improve the quality of teaching, to promote the culture of high-quality application-oriented talents. College sets up evaluation system, headed by the president, vice president, deputy head of teaching. After the completion of a rigorous assessment, 
the result has been given as outstanding, achievement, and failure. The male teachers under the age of 47 and the female teachers under the age of 45 must attend assessment. The results will serve as the annual assessment, professional and technical positions, appointment, arrange of teaching task, rewards and punishments.

In order to adapt to the characteristics of the application running at the University of Science and Technology and the Training Program in 2013 "training senior engineering and technical expertise", full-time teachers should have a deep theoretical knowledge and practical engineering ability. So, mechanical and power engineering college develop and implement a "teacher capacity building program". College upgrading scheme is divided into three categories: First, for the basic knowledge improvement of mechanical, the college made the overall plan and the whole faculties taked participation. By "mechanical products of digital design skills competition", the basic knowledge of mechanical has beed improved. Second, the professional skills have upgraded with the combination of teaching reform. The schemes have been presented by each teaching section (center) or courses term and the relevant professional teachers must take part in it.Third, the practice ability have been improved in the enterprise by combination of professional and personal research. July to September, 2014, nine young teachers were selected to enhance engineering practice in Beijing Metallurgical Mike Hydraulic Co., Ltd. and Chongqing Iron \& Steel (Group) Co., Ltd. Many teachers believe that the harvest of knowledge out of the books, and have the feelling of the limitations of their previous knowledge. It was agreed that this practice is necessary, and it can be used in the teaching work in the future. In the practice courses, teachers can make lecture closer to the actual production and develop practical talents.

\section{Respect to Courses Upgrading Scheme}

1、Three-dimensional software training: Those teacher who need to use three-dimensional design software in teaching and research have to take the training of three-dimensional software(Inventor).

2、Hydraulic principles and Rexroth hydraulic experimental system operation training: The training is divided into the primary and intermediate training. The primary training incluses hydraulic transmission principle, the basic design of the hydraulic system, Rexroth experimental systen use and operation. Teachers have been required to complete more than one hydraulic experiment independently. The intermediate training is the use and operation of the hydraulic proportional valve. The teachers must grasp the basic principles and the use of hydraulic proportional valves.

3. S7-300PLC control system use and programming training: Siemens S7-300 PLC is high-end systems and this system has been used in Rexroth experiment system. This training includes PLC wiring, operation and use, the use of PLC programming software, the basic experimental project programming. Teachers who teach hydraulic system have been required to use the control system and have the ability to guide students about hydraulic control experiments. It also requires the teachers who teach mechanical and electrical courses have to understand the use of PLC in hydraulic experimental. The intergration of electromechanical and hydraulic can be done, so the students of two fields can take full advantages of the hydraulic system and control systems.

\section{Practice Enhancement Programme}

Engineering practicals training on the growth and development of young teachers play an important 
role. With two young teachers from heat and power engineering section, for example, although there are often opportunities for them to contact the factory and some industry research groups in the previous learning and research process, but the knowledge mainly focus on the cognitive not the on-site operation of industrial systems and equipment, and integrated management of system. Although they mastered abundant theoretical knowledge in the process of learning and research in the university, but the practical application of theoretical knowledge in the industrial field is relatively lacking. Engineering problem is the original ecosystem, closely associated with the technology, software, etc. To turn this seemingly very specific problem into academic issues is crucial. Most teachers are not familiar to solve this problem and often can not see the engineering academic problems. So they can not solve engineering problems with academic theory. If you want to extract the academic issues from the project, you not only have the knowedge about the existing tools and the engineering technology, but also understand the practical engineering background. A good teacher should have the combination of both.

The teachers have worked Chongqing Iron \& Steel (Group) Co., Ltd. more than two months and realized that in order to apply the theoretical knowledge to the project and to serve the community, teachers must have engineering realities. Chongqing Iron \& Steel (Group) Co., Ltd. energy management and scheduling system is a unified management. iron, steel, continuous casting, hot rolling and other production processes needs, such as water, electricity and gas can be rendered in real time on energy control center interface implemented by the energy control center . For iron and steel enterprises, by energy management systems, it not only can achieve real-time monitoring of the energy system, but also can grasp the future trends in energy consumption through energy forecasting, scheduling energy to develop a preliminary plan to guide the implementation of future production. Therefore, it need to develop energy model single device to start, develop complete energy system piping network subsystems, flow transport models, energy systems and various energy forecasting model system, optimization scheduling mode.

Young teacher engineering practice training base should not only lay in enterprise. The university laboratory can be used as engineering practice base to strengthen the capacity of young teachers. Young teacher involved in the construction process of laboratory is good for the young teachers to improve their engineering practice abilities. University should cooperate with medium-sized enterprises to jointly build training base.In addition to the university laboratory, the university-enterprise cooperation base can be used as training base for the improvement of young teacher engineering practical ability. Some universities have established the College of Engineering and Technology Industrial Park. This is the practical base for research integration and provide strong environment for the training of young teachers in engineering practice ability.

\section{Summary}

In universities, young teachers have professional theoretical knowledge, a high level of research capability. At the same time, they become the main bearer of teaching activities. Their teaching abilities largely determine the quality of teaching and directly impact on the quality of education in universities. The teaching abilities of young teachers are obviously inadequate and seriously affect the quality of teaching. Therefore, scientific planning, training, training to improve teaching ability of young teachers are very important. Upgrading basic knowledge, combined with teaching reform and professional skills improvement, combined with professional and personal research improvement in the enterprises are effective methods to enhance the teaching abilities of teachers. 


\section{References}

[1] Mao Hongtao, Explore mechanisms to enhance the teaching ability of university teachers, China Higher Education, 201123

[2] Ma Qiang, Young college teachers to enhance the teaching ability of mechanisms, China Higher Education, 201209

[3] Chi Enron, Development of teaching ability of young Chinese Universities, Nanjing University, 2013

[4] Beam Jen Long, Xu Shengmei, New research teaching ability of Young Colleges - Taking Anhui Province as an example five new colleges, Chizhou College, 201003

[5] Ranhuaiminluo, Our young college teachers Review of Teaching Ability, month read Adult Education, 201209

[6] Wu Shengqing, Issues of local young college teachers training, Huangshi Institute of Technology (Humanities and Social Sciences), 201001

[7] Li Bin, Yan Bing, Young teachers to enhance Approaches, China Electric Power Education: In, 2014,300222

[8] Dingyouqing, Research and Practice and research innovation platform, Education and Career, 2009,3

[9] Ding Youqing,The teaching team building and quality engineering, Chongqing University (Social Sciences),2013,3, P194-196

[10] Zou Youjing, the vocation loyalty of university compensation management for young teachers and its influencing factors, Chongqing University (Social Sciences),2013,3, P163-166 